\title{
Reasons for International Institutional Inefficiency in the Governance of Transnational Challenges: Cases around the Globe
}

\author{
Qinfeng Jiang ${ }^{1}$, Chenyuan $\mathrm{Li}^{2}$, Kawing $\mathrm{Wei}^{3}$, Xike Yue ${ }^{4}$, Haoxi Zhang ${ }^{5 *}$ \\ ${ }^{1}$ The Experimental High School Attached to Beijing Normal University, Beijing, 100032, China \\ ${ }^{2}$ World Foreign Language Academy, Shanghai, 200233, China \\ ${ }^{3}$ Harrow International School Hong Kong, Hong Kong, 999077, China \\ ${ }^{4}$ Department of Economics, University of Washington, Seattle, 98195-4550, U.S.A \\ ${ }^{5}$ School of Law, Jiangxi University of Finance and Economics, Nanchang, 330032, China \\ *Corresponding author. Email: 2201802383@stu.jxufe.edu.cn
}

\begin{abstract}
This paper aims to analyze why international institutions are inefficient in solving global challenges by illustrating three cases concerning Arctic protection, Covid-19, and climate change. The paper concludes that the reasons are (1) the conflict of interests between states and (2) the weakness of international institutions in enforcing international law. In Arctic protection, this paper uses the case of Hans Island, a territorial dispute, a lack of common interests, and the Arctic Council's binding force contribute to this long-lasting problem. The pandemic becomes severe due to different interests between World Trade Organization (the WTO) and World Health Organization (WHO). In climate change, a conflict of interest between domestic priorities and global incentives leads to a lack of cooperation between states. Alongside the weak enforcement power of treaties and international institutions, the issue remains unresolved with the Paris Accords. From this, the paper arrives at two promotional measures: (1) introduce a dual compliance mechanism of punitive and promotional measures and (2) provide moral and global protection guidelines to place moral pressures on countries not abiding by the standards of international law.
\end{abstract}

Keywords: international law, inefficiency, international institutions, conflict of state interests, Arctic protection, Covid pandemic, climate crisis.

\section{INTRODUCTION}

The difficulties in the implementation of international law can be said to be inherent. From the current situation of global public governance in recent years, international law is not efficient in operation. The failure of the global public governance legal system is particularly prominent in global pandemic response, global climate change Governance, and Arctic governance. The root causes for the inefficiency of international institutions lie in the conflict of interests between state and global incentives and the weakness of international institutions in enforcement power that would ensure state compliance.

International institutions act as a composition of states that hold the defining power in controlling the enforcement and efficiency of these institutions. Hence, in this understanding, a reference should be made to Mearsheimer's theory. In 2014, John Mearsheimer's The
Tragedy of Great Power Politics publication gave people a completely different understanding of the entire international relationship.[1] Such a pessimistic theory of offensive realism analyzes the inefficiency of international institutions in the current system of International law. Military forces are essential for states to guarantee stability and ensure security in governing power. The same logic could be applied on an international scale, hence applicable to global institutions. Hence, military power holds to be a determining force in enforcing agreements between states, parallel to those within domestic parameters; however, international institutions lack such forces, so could not be efficient in the enforcement of rule intrinsically.

In addition, A Theory of Justice by John Rawls mentioned the idea's rights and justice in a society. Global justice needs states to reach their maximized 
legitimate expectations without harming others' interests, the same as individuals in the original status in the principles of justice. Therefore, international institutions should reconcile the will of nations and social contingency factors to be more effective.[2] The contradictions of state interests are prevalent in many world issues, and social contingency factors make citizens, and local aboriginals in various states of international institutions have different perceptions of goodness, making reconciliation more difficult. Therefore, the second reason International institutions cannot achieve sound effects is the irreconcilable difference between respective interests of states. These contradictions can also prevent International institutions from allowing participants in International institutions to achieve the greatest pursuit of good.

In this paper, three cases around the globe will be shown to prove that the reasons for institutional inefficiency are conflict of interests and institutions' lack of enforcement power: the first one is Arctic protection, the second one is climate change, and the third one is the Covid-19 world pandemic.

\section{CASE ANALYSIS: ARCTIC PROTECTION}

\subsection{Background}

Considering Arctic protection, the prominent international institution is the Arctic Council, an intergovernmental institution that addresses issues of the governments and the aborigines. The 1996 Ottawa Declaration [3] established the Arctic Council. However, no enforcement force is given to the resolutions in the institution by great powers. In general, the weakness of the Arctic Council is mainly due to the lack of recognition between states. Russian Federation (Russia) and the United States of America (U.S.) have conflicting interests, exacerbating disagreements among states. In addition, though states have different purposes regarding this region, the indigenous people add to the cultural diversity and complexity of the problems, leading to the perceived difference of good. As a result, lack of recognition of great powers and cultural consideration mainly bring about problems in the Arctic Council.

\subsection{Hans Island Case}

Recently, conflicts in the Arctic have become more evident because the Arctic is becoming more and more navigable. With more human activities and resource "war" between countries, territorial sovereignty is essential for claiming ocean zones, which brings out the major conflicts in the Arctic. The dispute of Hans Island is a typical example of a territorial dispute.

The Arctic Council has not held formal meetings and discussions on Hans Island, and such geopolitical issues are complex for states to resolve. The disputed island at stake is located in the middle of the Kennedy channel that separates Ellesmere Island, a part of Canadian territory, and Greenland, an autonomous country within the Kingdom of Denmark.[4] In such cases, the territorial claims made by the disputing parties might overlap, even though they are legal under the UNCLOS. The seabed around the Island contains bountiful oil and gas resources, and the Strait might become a new international shipping route, which makes states worry about their safety conditions. From the 1850 s to 1880 s, the British and American explorers did not have a state claim after discovering the island. Since 1933 when Denmark claimed Hans Island and became a part of them, Under Article 59, whenever a conflict arises between two coastal states, "the conflict should be resolved based on equity and in the light of all relevant circumstances, taking into account the respective importance of the interests involved to the parties as well as to the international community as a whole.'[5] Arctic Council's inaction on this dispute remains an issue to last for an extended period.

The main reason here is the difference of respective interests between Canada and Denmark. Although the cooperation between the two countries is very peaceful in many international relations, there will be more tension due to such irreconcilable conflicts of interest. There will also be the danger and threats of destroying the peace in the Arctic. Another reason for this long-lasting dispute is the lack of recognition of the territorial distribution standard by great powers in the Arctic region, resulting in less interference and reconciliation on geopolitical issues by the Arctic Council.

In addition, the territorial dispute on Hans Island contains cultural differences, not only the cultural differences between Canada and Denmark but also the Inuit. Since the 1300s, Inuit people have been considered likely to hunt on Hans Island. Territorial disputes must feel this cultural difference and the indigenous people's custom of hunting on the island.[6] As active participants in the Arctic Council, Inuit people can claim their rights to the Arctic Council. However, because countries resolve territorial disputes independently but not the Arctic Council, cultural differences are not reflected in the interactions, and indigenous people's rights are ignored. Therefore, in Hans Island, where cultural importance is paramount, achieving cultural identity and understanding is crucial. If territorial divisions and disputes affect the culture of the indigenous people, it will be devastating.

\subsection{Solution}

In the case of the Arctic Council, it is better to imitate the Antarctic Treaty to have the regulations stop for more territorial claims and changes. Also, the Arctic Council should include Inuit and other indigenous parties in the 
decision-making process of interest conflict. In order to balance the interests of all parties involved, more research and experts should play roles in unique regions like the Arctic to determine all parties' interests. In addition, the Arctic Council should ask great powers for recognition and protection to gain power.

\section{CASE ANALYSIS: COVID-19 PANDEMIC}

\subsection{Background}

From the known and verified information, the first case of pneumonia of unknown cause was identified in Wuhan City, China, on December 12, 2019.[7] Currently, "World Health Organization (WHO) is leading and coordinating the global effort, supporting countries to prevent, detect, and respond to the pandemic."[8] Under the circumstance of the worldwide pandemic disease, WHO plays its role in advising and supporting global public health. The functioning of WHO remains ineffective. WHO is relatively inexperienced in solving transnational health issues requiring international cooperation, because lack of recognition of great powers did not offer a chance for WHO to process.[9] The hardto-define global justice leads to irreconcilable interests conflict between states, causing a lack of communication and persuasive power in advising great powers also acts as a barrier to the efficient containment of Covid-19.

\subsection{Vaccine and Intellectual Property Law}

States should pursue the distribution of the vaccine in a manner aligned with global incentives. In the perspective of WHO, vaccines function as a shared global health property. However, vaccine-possessing countries prioritize vaccines' economic values instead of the benefit of global health. This intention is contrary to the will of WHO for a fair and equitable distribution. Since WHO cannot define a just distribution of legitimate expectations, these vaccine-possessing countries often use their intellectual property protection of vaccines as an excuse to avoid their international public health obligations to protect their economic interests.[10] Thus, the conflict between the state's economic interests and the public interest leads to their selective performance of international law.[11]

\subsection{International Institutions}

WHO takes the responsibility to monitor and address the Covid 19. International Health Recommendations is a binding treaty that binds 196 countries. There are two primary obligations of this treaty. Firstly, if an infectious disease outbreaks, governments should notify WHO. The country must declare. Second, every country in the world has the responsibility to build the capacity in its health care system to detect, prevent, and respond to infectious disease outbreaks, where WHO is responsible for helping mobilize an appropriate response.

WHO lacks enforcement power, because great powers have room for it, so it cannot impose sanctions on a country to prioritize economic interests following the International Health Recommendations. Instead, it can only provide suggestions. Problems including human rights keep appearing under the pandemic. It is difficult for people to make judgments. Hence, balancing vital interest lies on the individual country over that of the will of WHO.

\subsection{The Conflict Between the World Trade Organization (WTO) and WHO}

A conflict of interest between two important entities, the WTO and WHO, furthers the dispute. The conflict between the WTO and WHO functions to demonstrate a crossover between the two ideas. This conflict is due to lack of consideration between great powers on connecting international institutions. Hence, the states hold justifications from the WTO for their actions, though against global health benefits. During the pandemic, trade has been influenced and severely diminished, hence functions as a detriment to a nation's economy. Therefore, conflicts occur; for WHO, the priority is to address the Covid-19 pandemic, but for the WTO, former trades should still keep on. Both of them are under the structure of international law. This article leaves room for a country to be selective about which international law to follow or neglect. Hence, a misalignment between the goals of international institutions acts to debase the international legal system (in cases) to simply be a tool that a country could choose to justify the pursuit of state interests over those crucial in solving transnational issues.

\subsection{Solution}

In the case of the Covid-19 pandemic, states should elevate and redefine WHO's authority. WHO should have the right to know and monitor the domestic situation of public health status. WHO should have the right to send professionals and out-field employees to targeting countries, helping people to obey appropriate rules during the pandemic. Reaching the priority of the current situation - global health — is always essential. Reducing quiet diplomacy and adding more public condemnation should be considered as a method. Pressure from the outside tends to alter the situation of a country. 


\section{CASE ANALYSIS: CLIMATE CHANGE}

\subsection{Diverging State Interests in Relations to the Inefficiencies of Implementing Solutions to Solve Problems of the Global Commons}

Article 2 of the Paris agreement stipulates the longterm goal: to control the global temperature rise above the pre-industrialization level below two Celsius and strive to limit the temperature rise to $1.5{ }^{\circ} \mathrm{C}$ above the preindustrialization level. However, the meteorological observations records show 2015-2019 to be the warmest five years.[12]

When dealing with issues such as climate change, on the one hand, the difference of national interests is a factor leading to the inefficiency of international law in solving the problem of global climate change. These countries have conflicts between their interests determined by their economic structure and political status. On the other hand, the lack of coercive force of international institutions is also the reason for the insufficient implementation and low efficiency of international environmental law.

International institutions function as a composition of countries (incentivized by domestic interests); an agreement must be met between countries to fulfill global interests. Because states can determine the issues in international institutions, states without consensus will cause institutional inefficiency in reaching agreements or forming regulations. Hence, state actors remain the determinator for whether such agreements could be successful, especially in non-binding scenarios, as states are the direct actors that serve the purpose of carrying out non-consequential agreements on their accords.[13]

This analysis is supported by the idea proposed by Rosenau (1969) where he argues that to understand issues and implications of international discourse, an examination of internal affairs and domestic politics should first be analyzed. Though nations are often perceived in a unitary way[14], Putman (1988) pioneered a new perspective that enabled a two-level understanding. First, domestic constituents must accept a notion, then could international agreements be made.[15] Therefore, climate change through international law (foreign policy) must first be filtered through domestic politics. This, however, is impacted by incentives held by individuals that are ultimately determined by industry, energy dependency, and economic diversification. Following such, a state's political structure functions to determine the course of action taken as a result of domestic situations while providing incentives for actions. However, due to the difference in the composition of interests and issues, different countries would ultimately have discord in their approach to the way climate action should be taken.[16]

\subsection{The Case of The European Union and Saudi Arabia}

The European Union aims to reduce carbon emission by 20 percent by 2020 and 40 percent by 2030 . In addition to such, the measures implemented following the Paris Climate Accords allowed the EU to source 32 percent of electricity through renewable energy.[17] This plan could be possible as the European Union consists of states that are less dependent on the fossil fuel industry as the primary source of economic, social, and political structure because they are mainly great powers in world politics. Rather, society is centered around the tertiary sector [18]; therefore, as the factors of production (labor, capital, land, and enterprise) are not centered on industries that would inevitably drive up carbon emission: compatibility could be achieved through an alignment of state incentives and global agreements such as the Paris Climate Accord.

In contrast, Saudi Arabia is highly dependent on oil where the energy sector (oil and gas) contributed to $50 \%$ of the nation's GDP during 2019 and $70 \%$ of earnings through exports, where petroleum exports reached 261,530 million.[19] Through this economic lens, the nation is heavily tied to the oil industry. When analyzing the significance of a sector, socio-political-economic perspectives should be seen to have an interrelationship. Due to the significant economic dependency of oil, where most economic activity is heavily linked to oil production, socio-political implications need to be considered. A significant conflict of interest allows the continued extraction dominance that enables security but produces adverse effects in maintaining the clauses that would enable a successful commitment to the Paris Climate Accord. Therefore, due to the diverging interests concerning domestic reasons, the Paris Climate Accord becomes secondary to uphold as it follows a less immediate purpose being a non-consequential agreement that promotes climate action, so the stakes for the country to follow more immediate domestic concerns and not more the accord becomes immensely higher.

Hence, diverging state priorities would impact the efficiency and implementation of the Paris Climate Accord as it is a global problem, so it requires a global solution. Control of carbon emission on a singularity basis through climate action would not solve the scale needed to maintain secure control over the transnational issue. In understanding the economic perspective through the two countries, a justified explanation could be observed in regard to the hesitations of some countries compared to others, and that would ultimately cause an inefficient institution.

\subsection{The Weakness of International Institutions}

On the other hand, in terms of phasing out fossil fuels or achieving decarbonization of the global economy, 
international institutions do not have sufficient coercive force to ensure compliance with the treaty.

The Paris Agreement, which focuses on achieving carbon emission reduction targets, does not give its committee enough power to ensure the treaty's implementation. Disagreements between great powers and lack of standard for global justice cause this result. According to paragraph 2 of Article 15 of the Paris Agreement, the institutional form of the committee is to perform its functions in a non-confrontational and nonpunitive manner. The mechanism referred to in paragraph 1 of this article establishes the committee composed of experts and proponents to perform its functions transparently, non-confrontational, and non-punitive. Such requirements stem from the consideration of states sovereignty but directly lead to the lack of enforcement forces of the committee in ensuring states' compliance.

In addition, in terms of the implementation method design, the Paris Agreement has changed the "top-down" emission reduction mode of the Kyoto Protocol to the "bottom-up" mitigation mode of " independent national contribution and review.". This model makes it easy for the Paris Agreement to reach a unified opinion among countries. However, the agreement does not specify when states need to complete their promised emission reduction targets as the agreement does not have a binding force. The effectiveness of the agreement undoubtedly weakens dramatically. Because the agreement does not ensure topdown unified supervisions and clear emission reduction targets, the effectiveness depends on the state's independent contribution. Each contracting party abides by the contract, which will inevitably lead to the lack of enforcement of the agreement, thus reducing the realization of emission reduction targets, which means that international institutions are powerless or even in vain in this regard.

When dealing with issues such as climate change, on the one hand, the difference of national interests is a factor leading to the inefficiency of international law in alleviating climate change. The inefficient implementation of international law could be attributed to two underlying reasons for the inefficient implementation. First, conflicting state and global incentives are furthered because international institutions lack sufficient implementation power of agreements because of essential differentials between various states' economic structures and political statuses. Therefore, the unfulfillment of both criteria, as stated by the thesis, functions as the reasoning behind inefficiencies in improving climate change.

\subsection{Solution}

To ensure the effective implementation of climate action, the United Nations should establish a two-step guarantee system. One of the two mechanisms should be secured. First, to corroborate an alignment of interests between states. However, the first step guarantee is unlikely to be fulfilled due to intrinsic differences socially, politically, and economically. Hence, reliance falls heavily on the second mechanism where states should give international institutions a sufficient amount of power that could bring about a coercive effect, functioning as a method to ensure reasonable concessions between states despite conflicting interests.

\section{CONCLUSION}

Because of their contradictions of economic, social, or political position, the issue of differentials when approaching issues such as Arctic protection, the Covid pandemic and climate change acts as a factor responsible for the inefficiency of international law. In addition, the lack of enforcement power of international institutions regarding the three issues further exacerbates the severity in which international institutions remain ineffective in solving these transnational challenges.

The analysis of the three global governance cases suggests that we can change the inefficiency of international institutions in solving global issues in the following general ways.

First, international institutions need to set up a dual compliance mechanism of punitive and promotional measures to make them more capable of guaranteeing treaty compliance. In terms of punitive measures, a compliance guarantee mechanism is effective. Institutions should develop economic penalty systems whereby all parties pay a certain amount into a compliance guarantee fund, used as a penalty when they violate the agreement. This method would strengthen the enforcement of the agreement and also strengthen the compliance system of the agreement. At the same time, institutions should control the magnitude of the financial penalties. In terms of promotional measures, when the defaulting country has insufficient compliance capacity, it may be possible to provide the defaulting country the necessary assistance through technical and financial support, such as through the establishment of a pool of assistance funds for countries with insufficient compliance capacity and a pool of assistive technologies to facilitate the achievement of good compliance by the final countries. The basis and key to the effectiveness of the above mechanism are that it requires forming a broader consensus and cooperation among major countries.

In addition, a binding system of moral and public opinion around the globe is necessary. The international governance of global pandemic, climate change, and Arctic protection cannot rely on violence alone but on edification and moral image. The United Nations, the World Health Organization, and other international institutions are not simple utilitarian institutions. For 
international problems, democracy alone is not a good solution, and sometimes it is not a good solution simply by enforcement. It is more important to rely on the power of culture to put pressure on non-compliance and countries to promote active compliance so that international law can be more vital in global governance and the people of the world can obtain a higher level of well-being.

\section{REFERENCES}

[1] Mearsheimer, J. J. (2014). The tragedy of great power politics. WW Norton.

[2] Rawls, J. (1971). A theory of justice. The Belknap Press of Harvard University Press, Cambridge, Massachusetts.

[3] Ottawa Declaration (1996) https://oaarchive.arcticcouncil.org/handle/11374/85

[4] Hornackova, M. N. (2018) Hans Island Case- A territorial dispute in the Arctic. https://projekter.aau.dk/projekter/da/studentthesis/h ans-island-case--a-territorial-dispute-in-the$\operatorname{arctic}(9 \mathrm{bf} 41365-\mathrm{f} 87 \mathrm{f}-4 \mathrm{~b} 38-\mathrm{b} 96 \mathrm{a}-$ 52705356f067).html

[5] The United Nations Convention on the Law of the Sea (UNCLOS), 1982. Article 59.

[6] Canadian Geographic. (2013) "Whose Hans?". Hans Island: Time (archive.org)

[7] Zhangkai, J. C. Jing, S. 2019 Novel Coronavirus: Where We Are and What We Know. (2021) US National Library of Medicine National Institutes of Health Search database.

[8] World Health Organization. COVID-19 Contributions Tracker." Funding (who.int).

[9] Britannica, T. World Health Organization. (2021) Encyclopedia Britannica. https://www.britannica.com/topic/World-HealthOrganization

[10] Brink Lindsey. (2021) "Why Intellectual Property and Pandemics Don't Mix." Why intellectual property and pandemics don't mix (brookings.edu).

[11] World Health Organization. (2021) “Access and Allocation: How Will There Be Fair and Equitable Allocation of Limited Supplies?" Access and allocation: how will there be fair and equitable allocation of limited supplies? (who.int).

[12] World Meteorological Organization. (2019) Global Climate in 2015-2019: Climate Change Accelerates. https://public.wmo.int/en/media/press- release/global-climate-2015-2019-climate-changeaccelerates

[13] Bueno de Mesquita, B., Smith, A. (2012) "Domestic Explanations of International Relations.” Annual Review of Political Science., 15.1: 161-81.

[14] Wilkinson. D. (1970) Linkage Politics: Essays on the Convergence of National and International Systems. American Political Science Review., 64.2: 667-668.

[15] Putnam R. (1988) Diplomacy and domestic politics: the logic of two-level games. Int. Organ., 42:42760 .

[16] Bueno de Mesquita, B., Smith, A. (2012) "Domestic Explanations of International Relations." Annual Review of Political Science., 15.1: 161-81.

[17] National Geographic. (2021) Climate change report card: These countries are reaching targets. https://www.nationalgeographic.com/environment/ article/climate-change-report-card-co2-emissions

[18] European Central Bank. (2021) Structure of the Euro Area Economy. https://www.ecb.europa.eu/mopo/eaec/html/index.e n.html

[19] Organization of Petroleum Exporting Countries. (2021) Saudi Arabia facts and figures. https://www.opec.org/opec_web/en/about_us/169.h tm. 